\title{
Ziguezagueando com Ricardo Benzaquen no Departamento de História da PUC-Rio
}

Marcelo Jasmin*

O convite para escrever sobre a presença institucional de Ricardo Benzaquen de Araújo no Departamento de História da PUC-Rio produziu muitos temores. Em primeiro lugar, porque a vida profissional de Ricardo se confunde com a própria história daquele Departamento. À exceção de um período de licença entre 1988 e 1994, Ricardo viveu na PUC-Rio desde o início dos anos 1970 até a sua morte em 2017. Além disso, e talvez mais significativo, é que a sua presença como professor extrapola qualquer das narrativas quantitativas da vida profissional tão em voga hoje em dia. Qualquer um que vá aos registros numéricos não terá a menor possibilidade de avaliar a força e o impacto dessa presença. É verdade que Ricardo participou de inúmeras bancas de mestrado, de doutorado e de qualificação, e estas foram, em grande parte, registradas. Mas a natureza de suas arguições, as aulas, por vezes pequenas conferências, que pronunciava em cada uma destas ocasiões, costumava deixar seus ouvintes maravilhados, quando não embasbacados. A sua capacidade de aliar a imensa erudição, preservada por uma memória incomum, à criatividade intelectual, e a sua perícia em tomar um pequeno ponto da tese em questão para colocá-lo num contexto problemático extremamente complexo e bibliograficamente informado, são qualidades que não podem ser conhecidas pelas quantificações atuais. Sem falar de que isso envolvia uma performance muito própria que aliava momentos de aparente sonolência e desatenção com intervenções loquazes, radicalmente precisas em seus pontos, conceitualmente sofisticadas e dirigidas, sempre, para tornar mais digno intelectualmente o ponto em questão. Por vezes Ricardo demorava dois ou três minutos, no início de suas arguições, sem propriamente apontar para onde ia seu raciocínio, como se estivesse esquentando os motores de sua fala, deixando seus ouvintes um pouco perdidos. Mas de um momento para outro, em questões de segundos, aquela aparente preguiça e leseira se transformava para dar lugar a um gigante do pensamento e da argumentação. Só quem assistiu

* Marcelo Jasmim é professor do Departamento de História da Pontifícia Universidade Católica do Rio de Janeiro (PUC-Rio) e pesquisador do Conselho Nacional de Desenvolvimento Científico e Tecnológico (CNPq). E-mail: jasmin@puc-rio.br. 
sabe do que digo aqui. Tratava-se de presença, de um corpo e uma voz que ocupavam um espaço físico, que o preenchiam, e que jamais estiveram registrados nos anais digitais das avaliações.

E isso não se referia apenas às teses e dissertações. A qualquer momento do dia, ou mesmo da noite (pois Ricardo costumava sair da Universidade após as 22:00 horas quando fechava a biblioteca) encontrávamos o professor conversando com um aluno ou um colega sobre praticamente qualquer assunto para o qual ele tinha o que dizer e contribuir. Quantas vezes encontrei Ricardo, especialmente quando eu fazia a minha pós-graduação, e sofri uma imensa ansiedade porque, tendo contado a ele sobre algum argumento que eu elaborava, ele logo me respondia com uma enxurrada de ideias que muitas vezes me levavam para longe do caminho que eu imaginava dever percorrer - e uma lista de referências bibliográficas apontadas para várias alternativas ao meu argumento e que eu sabia que jamais daria conta de ler. Por vezes era necessário insistir que o caminho era outro e que embora aquilo que ele me dizia fosse interessantíssimo, eu buscava outras hipóteses e conexões intelectuais. Então Ricardo respirava um pouco mais fundo, dizia algo como "Então vamos lá", e travava um diálogo para dentro da conversa que eu propunha, desenvolvendo possibilidades e sugestões bibliográficas que, se não eram as suas preferidas, eram absolutamente úteis para o seu ouvinte.

E esse era o cotidiano de Ricardo. Fosse numa reunião de Departamento, num cafezinho nos pilotis, num encontro no corredor ou no restaurante Couve-Flor, dentro do campus, em frente de um prato de comida sempre de tom amarelado e regado a latas de Guaraná Antártica Zero, ele estava sempre pronto a conversar, ensinar, orientar, problematizar, mostrar o que havia de preconceituoso ou de impreciso no que se falava e, especialmente, mostrar alternativas. Nada disso foi quantificável, nada disso foi avaliado pelas muitas comissões responsáveis, dentro ou fora da Universidade, e sou testemunha de sua infelicidade, por vezes aguda, nascida pela ausência de reconhecimento desse seu trabalho diário, intenso, público, formador. A produção acadêmica e intelectual tem sido contada por artigos publicados em periódicos qualificados por pares e pontuados em função de critérios compartilhados pelos comitês de que fazemos parte. Por vezes se dá importância ao número de teses e dissertações orientadas como parte da produção de um professor. A participação em congressos e seminários também é vista, mas como uma espécie de contexto geral da interação, e em escala muito secundária as bancas de que se participa. E boa parte, senão a maioria, dos jovens professores e pesquisadores de hoje já operam como se 
isso fosse tudo.

Mas não é. Sem dúvida Ricardo publicou livros e artigos, alguns dos quais são referências obrigatórias como o "seu" premiado Gilberto Freyre, o "seu" Capistrano de Abreu, e o "seu" Joaquim Nabuco que começava a aparecer de modo inovador e no contexto da discussão contemporânea da subjetividade e do direito natural. Digo o "seu" porque de fato esses autores tão lidos e já clássicos da literatura histórica e sociológica brasileira ganharam em suas mãos uma identidade distinta, a partir de um viés de leitura preocupado, por vezes obsessivamente, de mostrar o que ninguém vira antes, mas que estava lá e que podia ser examinado a partir de um olhar formado por uma deglutição bibliográfica rara. Seus livros e artigos continuarão sendo lidos por qualquer um que se interesse pela vida brasileira e por suas expressões intelectuais, e gerarão os institucionalmente desejáveis "fatores de impacto". Mas talvez devêssemos prestar mais atenção ao que não se quantificou, nem se quantificará. Os títulos de seus textos, por exemplo, mereceriam ser premiados: "Ronda noturna", "O linho e a seda", "Terra de ninguém", "Raios e trovões", "Castelos no ar", "A cidade secreta", "Chuvas de verão", "O mundo como moinho"...

Ricardo atravessou muitas sendas distintas, sempre mantendo uma relação dialógica entre a história, a sociologia e a antropologia, e o livro de escritos recolhidos que ele organizava antes de morrer já tinha título sonoro e significativo: Zig-zag. Ricardo ziguezagueou um bocado na sua trajetória profissional na PUC, naquela sua parte que não deixa rastros estatísticos, nas suas falas cotidianas, em suas intervenções nos debates de todo dia, em suas conversas fortuitas ou programadas, em suas arguições. Eu devo a Ricardo Benzaquen as primeiras leituras de Alexis de Tocqueville e de Reinhart Koselleck que são inseparáveis de minha trajetória e a de meus alunos. E o seu tesouro intelectual se prolonga nas inúmeras teses e dissertações que orientou com enorme e raríssima dedicação e que constituem uma tradição particular de pesquisa cultural. Neste próximo semestre acadêmico de 2017, ex-alunos de Ricardo ministrarão em conjunto um curso na Pós-graduação em História Social da Cultura da PUC-Rio, cada um deles apresentando um dos inúmeros textos que marcaram as suas formações. Uma homenagem bela, intelectualmente digna e que também não contará para nenhum índice que hoje se considera relevante por aí.

Quando resolvi escrever esse brevíssimo registro da passagem de Ricardo pelo Departamento de História da PUC, me dei conta de como muitas de suas contribuições estão sendo esquecidas na passagem do tempo, pela 
mudança geracional por que passa o Departamento e a Universidade, e pela natureza dessa presença que nem sempre deixou registros documentais. Resolvi, então, registrar alguns poucos fragmentos da presença institucional de Ricardo antes do início das atividades do Programa de Pós-graduação em História Social da Cultura em 1985, do qual ainda temos boa memória.

Ricardo ingressou como estudante de Sociologia no início da década de 1970 e transferiu-se para o curso de História, segundo alguns de seus colegas, fugido das disciplinas de estatística de que não gostava ou para as quais não se sentia vocacionado. Formou-se Licenciado em História em dezembro de 1974 e já no ano seguinte foi contratado pelo Departamento como professor horista. Ricardo já fora monitor em algumas disciplinas daquele Departamento no ano anterior e demonstrara que sua já notória vitalidade intelectual se encontrava com a vocação do professor. Contratado, sua estreia como professor foi lecionando a disciplina de Fundamentos da História Antiga e Medieval, quando apresentou uma leitura de A cidade Antiga, de Fustel de Coulanges, entre outras, e no semestre seguinte, na disciplina de História Medieval, um curso sobre Michelet e a feiticeira, dando início à sua longa trajetória, jamais abandonada, de lidar com os temas históricos privilegiando a leitura de obras clássicas ou de grande densidade intelectual. (Foi assim que, em 1980, quando fui seu aluno em História da América III, tive contato com A democracia na América de Alexis de Tocqueville). Foi um sucesso.

A partir de então, Ricardo lecionou disciplinas de praticamente todas as áreas de conhecimento do Departamento - Antiga, Moderna, Contemporânea, América e Teoria da História, além da Medieval - com a notória exceção de História do Brasil, o que causava, para ele e para alguns de seus colegas, certo estranhamento dado que suas pesquisas, desde a época do CPDOC, estiveram voltadas para o pensamento brasileiro. Talvez não houvesse muito espaço para o tipo de reflexão mais teórica e mais temática de Ricardo nas disciplinas obrigatórias da área, marcadas pela formação mais abrangente nos períodos da história brasileira - colônia, império e república. Talvez houvesse um excesso de reverência de Ricardo à erudição documental e historiográfica necessária para enfrentar tais cursos com seriedade, como ele reconhecia no seu antigo professor, e decano da área de História do Brasil no Departamento, Ilmar Rohloff de Mattos. O fato é que nem mesmo disciplinas eletivas sobre as suas pesquisas sobre Plínio Salgado ou sobre Gilberto Freyre aconteceram na graduação, e essa "lacuna" perdurou até o fim de sua vida.

Em meados dos anos 1980 Ricardo já estava associado à área de 
estudos de Teoria da História, na qual ele se sentia mais à vontade tanto para dar asas à sua infinita erudição, como para ministrar cursos que não apresentavam uma inscrição disciplinar unívoca, permitindo um trabalho acadêmico nas interseções entre a história, a sociologia e a antropologia, esta última a área de sua formação pós-graduada no Museu Nacional. Foi nesta área de Teoria da História que Ricardo também pode rever e renovar, com sua notória criatividade, os ensinamentos que aprendera com dois de seus antigos mestres puquianos, Francisco Falcon e Luiz Costa Lima, sendo que Luiz permaneceu como a sua principal referência intelectual brasileira até o final da vida.

Foi também esse trânsito livre entre as diversas áreas de conhecimento que levaram Ricardo a ser convidado como assessor do Decanato do Centro de Ciências Sociais, entre 1983 e 1987, quando participou ativamente da criação, e posteriormente da coordenação, de uma nova disciplina, iniciada em 1984, nomeada "Introdução às Ciências Sociais". "ICS", como a chamávamos pela sigla, tinha a duração de dois semestres e era oferecida no primeiro ano de todos os cursos daquele Centro, no momento em que uma reforma curricular dissolveu o antigo Ciclo Básico que, ao longo de muitos anos, ofereceu cadeiras de História, Sociologia, Antropologia, Ciência Política e Economia aos alunos do Centro de Ciências Sociais. O decano, à época, o professor Isaac Kerstenetzky, montou uma equipe integrada por Otavio Velho e Isabel Ribeiro (e talvez por outros professores), para levar a cabo a reforma curricular, e Ricardo participou da elaboração do programa da nova disciplina, coordenou a sua implantação e a ministrou. Uma das ideias inovadoras era a de que a disciplina deveria ser oferecida por professores de vários Departamentos, e isto de fato aconteceu (minha memória talvez se engane e certamente há esquecimento, mas do que recordo, nos anos iniciais da disciplina foram seus professores: José Carlos Rodrigues, Marcio Goldman, Marcos Veneu, Ovídio Abreu, Ricardo Barbosa, Roberto Magalhães, Sonia Giacomini, Wandir Hagge e eu...) No primeiro semestre, tratávamos de discutir a historicidade ou o caráter socialmente construído dos saberes, da verdade, das ciências sociais e dos fenômenos humanos, e leituras como A grande transformação, de Karl Polanyi, A verdade e as formas jurídicas de Michel Foucault e "Tempo, disciplina do trabalho e capitalismo industrial" de E. P. Thompson, se combinavam com um grupo mais variável a depender do professor. No segundo semestre, ministrávamos autores clássicos da tradição das ciências sociais, especialmente Durkheim, Marx e Weber, organizados a partir de temas que cada professor escolhia. Para mim, este foi um momento decisivo 
de inflexão intelectual, quando deixei de ministrar cursos gerais de História do Mundo Contemporâneo marcados, à época, por perspectivas de viés mais econômico, com suas bibliografias sobre a transição feudal-capitalista e sobre a passagem do capitalismo liberal para o capitalismo monopolista.

Não sei dizer exatamente quanto tempo durou a experiência de ICS, mas ao longo da década seguinte as várias reformas curriculares, quase sempre orientadas para a especialização disciplinar e a formação de profissionais para as exigências de mercado, acabaram por esvaziá-la. A disciplina ainda existe e é ministrada por professores do Departamento de História aos alunos de graduação do curso de Economia da PUC-Rio, em um semestre, mas o ímpeto de reunir um corpo docente de várias origens disciplinares para uma experiência intelectual e pedagógica comum esmaeceu neste caso, permanecendo a sua ideia inicial de tratar de temas comuns às ciências sociais de um ponto de vista interdisciplinar.

A interdisciplinariedade, entretanto, jamais foi abandonada na atuação profissional de Ricardo e marcou a história do Departamento de História desde os anos 1980. Momento precioso dessa perspectiva foi a criação, em 1985, do programa de mestrado em História Social da Cultura que apostou, de modo inovador, no diálogo entre áreas diversas e compôs o seu corpo docente com profissionais oriundos de tradições disciplinares diversas, como a Economia, a Sociologia, a Antropologia, a Ciência Política, a Arquitetura, a Literatura e a Arte, além, é claro, da própria História. Ricardo teve um papel determinante na defesa de uma experiência desta natureza, raríssima em nosso meio acadêmico, e foi um dos formuladores mais ativos da estruturação da pós-graduação, de sua área de concentração e de suas linhas de pesquisa. Dentre os professores do Departamento de História que fundaram aquele programa, certamente era ele quem tinha maior familiaridade com os temas da história da cultura. Mas este é um outro capítulo da história da presença institucional de Ricardo que merece um exame muito cuidadoso. Fica para outra oportunidade.

\section{Recebido em}

março de 2017

Aprovado em

maio de 2017 